\title{
Manufacturing Polycrystalline Pellets of Natural Quartz for Applications in Thermoluminescence Dosimetry
}

\author{
Álvaro Barbosa de Carvalho Junior , Thiago Fernandes Barros ${ }^{\mathrm{b}}$, \\ Pedro Luiz Guzzo ${ }^{\mathrm{b} *}$, Helen Jamil Khoury ${ }^{\mathrm{a}}$ \\ a Department of Nuclear Energy, Federal University of Pernambuco - UFPE, \\ CEP 50740-540, Recife, PE, Brazil \\ ${ }^{\mathrm{b}}$ Department of Mining Engineering, Federal University of Pernambuco - UFPE, \\ CEP 50740-530, Recife, PE, Brazil
}

Received: October 5, 2011; Revised: April 6, 2012

\begin{abstract}
This paper describes the manufacturing process of quartz-pellets and shows their potential use as thermoluminescence dosimeters (TLD) for those applications where low-levels of ionising radiation are present. Two batches of cold-pressed pellets were produced and their resistance were evaluated by vibration tests and weight-loss measurements. The batch manufactured with $75 \times 150 \mu \mathrm{m}$ particles showed enough resistance to be employed as TLD. The dosimetric properties of the $310{ }^{\circ} \mathrm{C}$ peak appearing in the glow curves of these pellets were characterized together with commercial TLD-100 units using $\gamma$ - and X-ray beams with different energies. The uncertainties related to reproducibility and stability of the TL signal were better than $10 \%$. The sensitivity and the linearity of the TL response of quartz-pellets were better than that measured for TLD-100 for doses ranging from 0.5 to $200 \mathrm{mGy}$. The energy dependence of the quartz-pellets was higher than that of TLD-100 but it cannot be considered a restriction to their use in clinical procedures and industrial applications.
\end{abstract}

Keywords: quartz, cold-pressed pellets, thermoluminescence, radiation dosimetry

\section{Introduction}

Thermoluminescence (TL) dosimetry is a well established technique to measure ionising radiation released from natural radionuclides, artificial sources of $\gamma$-, $\beta$ - and $\mathrm{X}$-rays and even cosmic radiation. The principle of TL dosimetry is based on the statement that ionising radiation produces free electrons, some of which being trapped by point defects existing in the crystalline lattice of an insulator material. After being exposed to ionising radiation, the TL material emits light while they are heated. The intensity of the emitted light is proportional to the number of trapped electrons and therefore to the amount of absorbed radiation. Since the general description of TL applications reported by Daniels and colleagues ${ }^{1}$, TL dosimetry has been useful in areas requiring personal and environmental monitoring, clinical procedures and industrial applications. A variety of TL dosimeters (TLD) manufactured with different materials and geometries and capable to measure doses from $10^{-6}$ to $10^{3} \mathrm{~Gy}$ is now available, but the crescent use of ionising radiation has continuously encouraging new investigations in TL materials ${ }^{2-6}$.

TL emission of $\alpha$-quartz has extensively been used in retrospective dosimetry, in particular for dating archaeological and geological materials containing quartz grains such as sediments, burnt stones and fired clays ${ }^{7-9}$. TL glow curves of quartz grains usually found in sediments and rocks or even prepared from single-crystals are composed

*e-mail: pguzzo@ufpe.br by several peaks appearing near $110,170,320$ and $370{ }^{\circ} \mathrm{C}$. These peaks are not useful to TL dosimetry due to its low stability $\left(110^{\circ} \mathrm{C}\right)$ or its low sensitivity $(170,320$ and $370{ }^{\circ} \mathrm{C}$ ) for the dose range used in clinical procedures such as radiotherapy and diagnostic radiology and many industrial applications ${ }^{2,4}$. To the best of our knowledge, quartz as a TLD material has only been used during the treatment of food with ionising radiation because this mineral is present in dust particles that are naturally deposited on farming products $^{10}$. However, combining $\gamma$ doses in the order of $25 \mathrm{kGy}$ and heat-treatments at $400^{\circ} \mathrm{C}$, it has been shown that the TL intensity of some quartz crystals in $280-320^{\circ} \mathrm{C}$ region can be sensitized more than 1000 times $^{11,12}$. Until now, the application of this result in TL dosimetry was carried out using quartz discs in the single-crystal form manufactured by ultrasonic machining and lapping ${ }^{13,14}$. As a result, it was possible to assess doses as low as $10^{-3} \mathrm{~Gy}$ with satisfactory reproducibility. At the same time, the effect of particle size in the TL response of the sensitized peak near $300{ }^{\circ} \mathrm{C}$ was analysed in ten size fractions classified between $38 \mu \mathrm{m}$ and $5 \mathrm{~mm}^{15}$. It was shown that the $150 \times 300 \mu \mathrm{m}$ size fraction has the highest TL response after being irradiated with testdoses equal to $50 \mathrm{mGy}$ of $\gamma$ radiation.

The possibility of using particles in the manufacturing process is crucial because the TL response of quartz is primarily affected by the population of impurity-related point defects acting as electron traps or recombination centers ${ }^{16,17}$. As a natural resource, the distribution of impurity-related 
point defects is very sensitive to the conditions into which quartz crystal was grown ${ }^{18}$. The heterogeneity in the spatial distribution of lattice impurities is a common feature in natural single-crystals. After sensitization, it was observed that the TL intensity of the sensitised peak near $300{ }^{\circ} \mathrm{C}$ considerably varies even from specimens obtained from the same crystal ${ }^{12}$. In principle, this heterogeneity can be reduced by powdering and homogenization procedures.

To be employed in radiation dosimetry, a TL material should have certain features allowing an accurate measurement of the absorbed dose. The main properties are: sensitivity; reproducibility and long term-stability of the stored information; linearity of the TL signal with radiation dose and low dependence of the TL emission on the photon energy ${ }^{2-4}$. It is also necessary to find a suitable procedure to manufacture low-cost TLDs with enough resistance against handling and environmental factors such as humidity and solvents. Thus, the aim of this study is to propose an alternative procedure to manufacture low-cost TLDs using sensitized quartz particles and to characterize their dosimetric properties that are important for clinical and industrial applications.

\section{Manufacturing Process}

Besides the dependence of TL response with particle size, two features of sensitized quartz had to be considered during the implementation of the manufacturing process of quartz-pellets. The first point was the necessity to find a satisfactory media to agglomerate quartz particles. Due to the direct piezoelectric effect, quartz became electrically polarized under mechanical stress and it is possible that quartz particles develop electrical repulsion between each other during the use of stress. Thus, the binding media should neutralize such effect without affecting the original TL intensity of the sensitized peak. The second point was the understanding that the TL intensity of the sensitized peak decrease considerably when quartz is exposed to temperatures higher than $400{ }^{\circ} \mathrm{C}^{19}$ hindering the use of sintering procedures in the production of quartz-pellets. These constraints let us to adopt a cold-pressed manufacturing

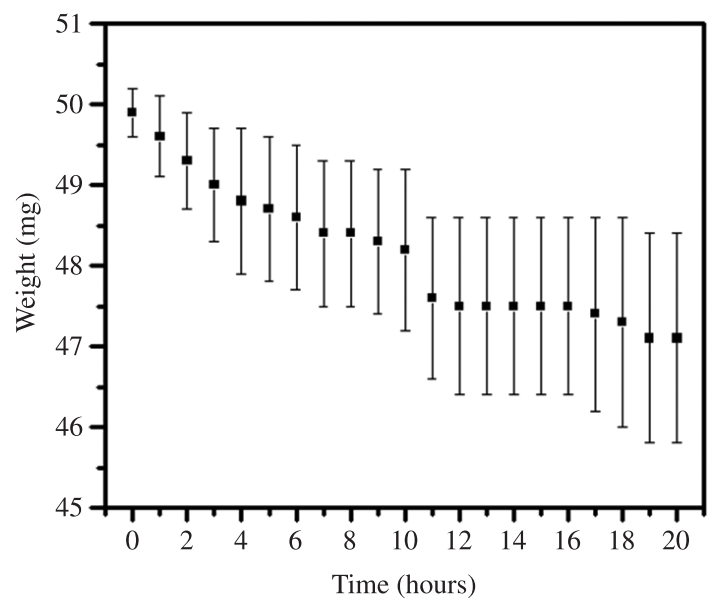

(a) $150 \times 300 \mu \mathrm{m}$ procedure and to use PTFE (polytetrafluoroethylene; also known as Teflon) as the binding media. Besides its thermal resistance up to $400{ }^{\circ} \mathrm{C}$, PTFE was chosen due to two reasons: (i) it does not shown TL signal in the temperature range of $200-400{ }^{\circ} \mathrm{C}$ for doses lower than $1 \mathrm{~Gy}$; (ii) it was successfully used in the production of other dosimeters ${ }^{20-22}$. Others binding media were tested (kaolin, montmorillonite and carboximetilcellulose) but the results were not satisfactory due to different reasons $\mathrm{s}^{23,24}$.

The crystal employed to produce the quartz-pellets was a single-crystal taken from a deposit located in the district of Solonópole (Ceará State, Brazil). Fragments of this crystal were cleaned with acetone for 15 minutes using an ultrasonic bath and were manually crushed using an agate mortar and pestle. The crushed particles were classified in two size fractions $(75 \times 150 \mu \mathrm{m}$ and $150 \times 300 \mu \mathrm{m})$ by using stainless-steel sieves. The size distribution of each fraction was measured with a laser particle size analyzer; model Malvern Mastersizer 2000 with the Hydro 2000MU sample dispersion accessory. The mean particle size $\left(\mathrm{D}_{\mathrm{m}}\right)$ corresponds to the aperture associated with $50 \%$ of passing material. The $\mathrm{D}_{\mathrm{m}}$ values found for the fractions $75 \times 150 \mu \mathrm{m}$ and $150 \times 300 \mu \mathrm{m}$ were 138 and $304 \mu \mathrm{m}$, respectively. Aliquots of $5 \mathrm{~g}$ of each size fraction were sensitized with $\gamma$-rays and heat-treatments according to the procedure described before ${ }^{15}$.

The quartz-pellets were manufactured by pressing a homogeneous mixture of quartz particles and flocculated PTFE (DuPont) at room temperature using a die manufactured by stainless-stee ${ }^{23,24}$. The ratio of quartz:PTFE in the mixture was $1: 1$ by mass. The compressive force $(5 \mathrm{kN})$ was supplied by a standard hydraulic press. Thirty pellets with approximately $50 \mathrm{mg}, 6 \mathrm{~mm}$ diameter and $1 \mathrm{~mm}$ thick were manufactured with particles of each size fraction. In order to improve the mechanical resistance without reducing the TL sensitivity, the two batches of pellets were progressively heat-treated in a muffle furnace at $400{ }^{\circ} \mathrm{C}$ during periods from 1 to 20 hours. After each step of heating (1 hour), the pellets were weighted in an analytical balance $(0.0001 \mathrm{~g})$. Figure 1 shows the mean values of the weight of the pellets measured after each step of heat-treatment. Throughout the

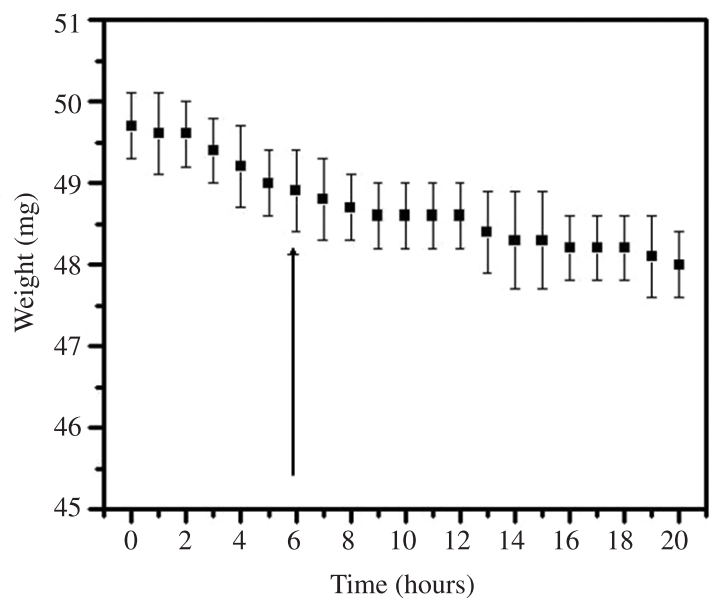

(a) $75 \times 150 \mu \mathrm{m}$

Figure 1. Weight of quartz-pellets measured during the cumulative heat-treatments up to 20 hours. 
heat-treatments, it was observed that the standard deviation related to each mean weight-value was larger for those pellets manufactured with $150 \times 300 \mu \mathrm{m}$ particles. It was also noticed that the mean weight-values decreased more quickly for these pellets.

Figure 2 show surface images obtained by scanning electron microscopy (SEM) of the pellets manufactured with each particle size. SEM micrographs were obtained with a JEOL-JSM-6460 microscope $(30 \mathrm{kV})$ after the pellets being coated with a carbon layer. These micrographs were obtained after completing all the heating-weighting cycles. The size of voids noticed in these micrographs explains the higher variability of the weight-values for the pellets manufactured with coarser particles, suggesting a poor cohesion with the PTFE media. Thus, although the TL sensitivity of $150 \times 300 \mu \mathrm{m}$ particles is approximately 1.5 times higher than that measured with $75 \times 150 \mu \mathrm{m}$ particles ${ }^{15}$, the surface integrity of the quartz-pellets manufactured with coarse particles is more susceptible to disintegration. Taken into account the results shown in Figures 1 and 2, a new batch containing 60 quartz-pellets was manufactured with $75 \times 150 \mu \mathrm{m}$ particles. The heat-treatment was performed during 6 hours without interruption. In average, the weight, the diameter and the thickness of the pellets of this batch was $(48.78 \pm 0.90) \mathrm{mg},(6.02 \pm 0.05) \mathrm{mm}$ and $(0.96 \pm 0.05) \mathrm{mm}$, respectively.

\section{Resistance to Disintegration}

In order to confirm that quartz-pellets has enough resistance to be employed in TLD procedures, 15 units of the new batch manufactured with $75 \times 150 \mu \mathrm{m}$ particles were submitted to vibration tests as follows. Firstly, the surface roughness of each pellet was measured with a Mitutoyo Surftest SJ-400 profilometer using a cut-off value of $0.8 \mathrm{~mm}$. Three profiles were obtained in random directions in both faces of each pellet. The centre-line average $\left(R_{a}\right)$ and the peak-to-valley height $\left(\mathrm{R}_{\mathrm{zDin}}\right)$ were chosen to characterize the surface roughness. The pellets were weighted after this procedure. Then, a group of 5 pellets was submitted to vibration into an ultrasonic bath apparatus operating at

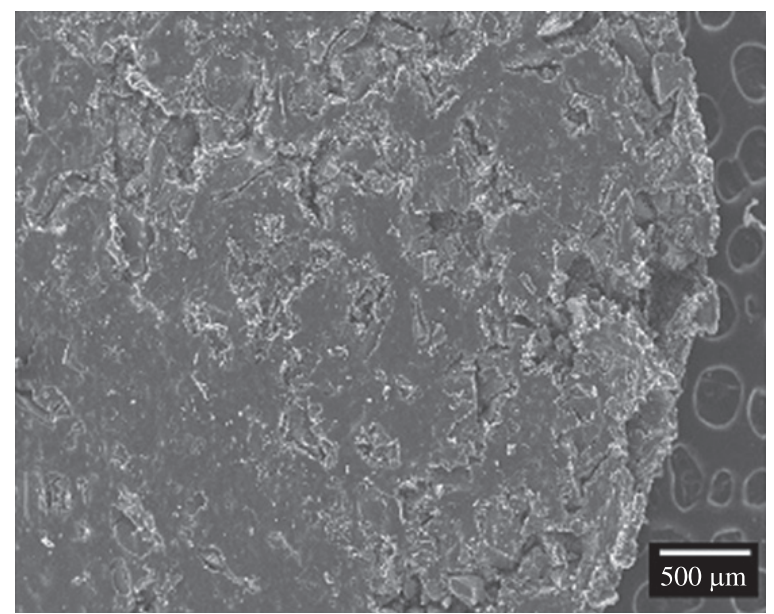

(a) $150 \times 300 \mu \mathrm{m}$
$40 \mathrm{kHz}$. Each pellet was put into a $100 \mathrm{~mL}$ beaker and the arrangement was placed inside the ultrasonic basket filled with water. Ultrasonic tests were carried out progressively from 2 to 60 minutes. After each time-interval, the weight of each pellet was measured. A second group of 5 pellets was submitted to vibration by using a Rot-up apparatus, which is currently used in dry sieving procedures. This equipment vibrates at $100 \mathrm{~Hz}$ but with higher amplitude than the ultrasonic cleaner. Each pellet was placed inside a $40 \mathrm{~mL}$ plastic flask and the arrangement was shaken with cumulative times up to 60 minutes. The weight of each pellet was measured after each step.

Figure 3 summarizes the variation of the weight of the quartz-pellets as a function of the time of each vibration test. It is observed that the weight of the pellets was not affected by the vibration conditions imposed by the ultrasonic cleaner. Similarly, besides a small weight-loss $(<1 \%)$ measured after the initial 5 minutes of vibration, the severity of the test carried out in the Rot-up apparatus did not affect the weight-values significantly. The mean values of $R_{a}$ and $\mathrm{R}_{\mathrm{z}}$ measured before and after completing the vibration tests are also shown in Figure 3. It is observed that the surface roughness parameters were not affected by the vibration tests. SEM analysis showed that the cohesion between quartz particles and PTFE was not affected by the vibration tests. Taking into account these results, it is concluded that the quartz-pellets manufactured with $75 \times 150 \mu \mathrm{m}$ particles has sufficient resistance to be manipulated during the dosimetric procedures.

\section{Dosimetric Properties}

The main dosimetric properties of the quartz-pellets were characterized with a group of 30 specimens manufactured with $75 \times 150 \mu \mathrm{m}$ particles as follows.

\subsection{Glow curve characteristics}

The glow curve shows the intensity of the TL emission as a function of time or temperature. It can be recorded with a constant heating rate (slope mode) or fast heating rates (step-heating mode). A typical TL glow curve recorded in

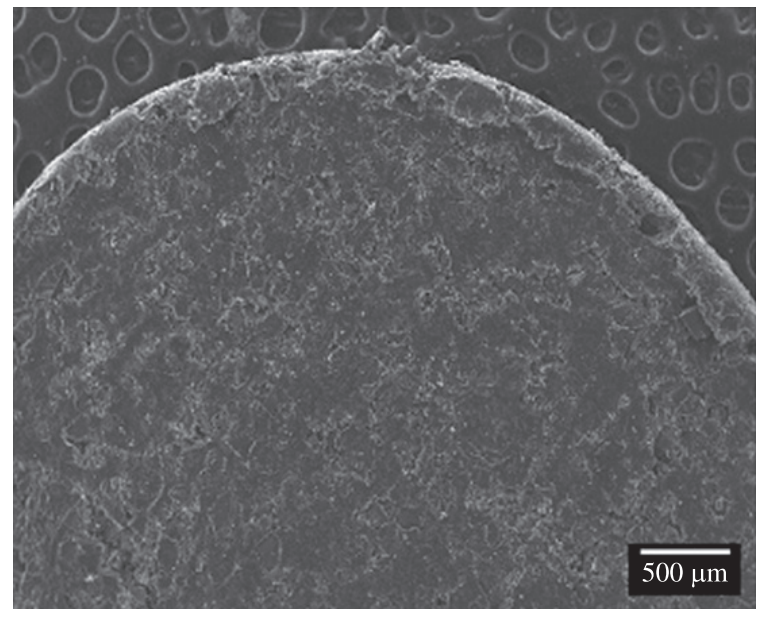

(b) $75 \times 150 \mu \mathrm{m}$

Figure 2. SEM micrographs of quartz-pellets produced with different particle sizes. 
the slope-mode is shown in Figure 4a. The specimen was irradiated with a test-dose of $50 \mathrm{mGy}$ using an irradiator of ${ }^{60} \mathrm{Co}$ with a dose rate close to $7 \mathrm{~Gy} / \mathrm{h}$. The glow curve was recorded with a heating rate equal to $2{ }^{\circ} \mathrm{C} / \mathrm{s}$ from 50 to $400{ }^{\circ} \mathrm{C}$, using a 3500 Harshaw $^{\mathrm{TM}}$ reader equipped with a 9125-B photomultiplier tube. Two TL glow peaks were observed: one near $100^{\circ} \mathrm{C}$ and the other near $310^{\circ} \mathrm{C}$. The peak near $100{ }^{\circ} \mathrm{C}$ corresponds to the so-called $110^{\circ} \mathrm{C}$ peak, which is usually observed in quartz grains extracted from sediments and single-crystals of various origins ${ }^{7-9}$. This peak shows thermal fading at room temperature and due to this reason is not suitable for TL dosimetry ${ }^{25,26}$. Thus, the peak near $100{ }^{\circ} \mathrm{C}$ was not considered throughout this study. The sensitized peak appearing near $310^{\circ} \mathrm{C}$ is at least one hundred times more intense than the well-known peaks occurring near 325 and $375^{\circ} \mathrm{C}$. The sensitized peak in quartz-pellets occurs in a higher temperature than that observed in free quartz grains and single-crystal discs where the peak maximum temperature is near $280^{\circ} \mathrm{C}^{15,19}$. A kinetic analysis of this peak showed that the activation energy and its shape remain unchanged even after 190 hours of annealing (accumulated) carried out at $400{ }^{\circ} \mathrm{C}^{[27]}$. These results show

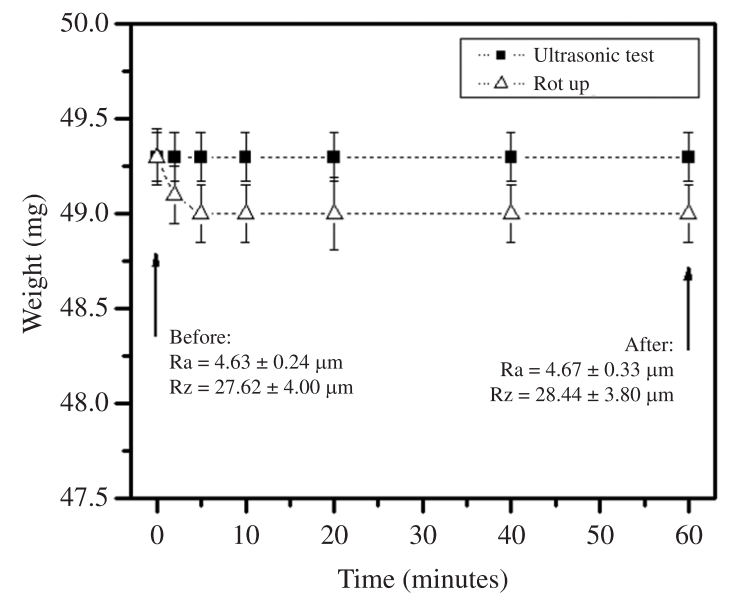

Figure 3. Weight and surface roughness parameters of quartz-pellets measured during the vibration tests.

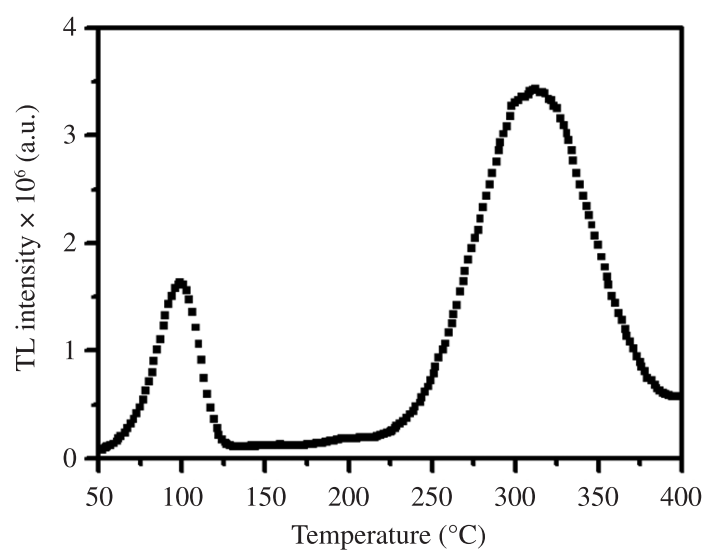

(a) $50 \mathrm{mGy}$ of $\gamma$-rays $\left({ }^{60} \mathrm{Co}\right)$; heating rate: $2{ }^{\circ} \mathrm{C} / \mathrm{s}$ that quartz-pellets has the preliminary characteristics suitable to a TLD material, i.e., the dosimetric peak is simple in shape; it occurs separately between 200 and $400{ }^{\circ} \mathrm{C}$ and it has the thermal stability required for reusability.

Figure $4 \mathrm{~b}$ shows a typical glow curve of a quartz-pellet measured in the step-heating mode. This curve was measured with a $2800 \mathrm{M}$ Victoreen reader, equipped with a 9250-B07 photomultiplier tube, using the step parameters as follows: 10 seconds from room temperature to $200{ }^{\circ} \mathrm{C}$; 25 seconds from 200 to $350{ }^{\circ} \mathrm{C}$. The first and second peaks correspond to the 100 and $310^{\circ} \mathrm{C}$ glow peaks, respectively.

\subsection{Reproducibility and stability of TL response}

In order to evaluate the reproducibility of the TL response, the sequence annealing, irradiation and TL read-out was carried out five times. The pellets were irradiated in air with a test-dose of $10 \mathrm{mGy}$ using an irradiator of ${ }^{137} \mathrm{Cs}$ with a dose rate close to $41 \mathrm{mGy} / \mathrm{h}$. In order to guarantee the electronic equilibrium, the pellets were fixed behind a $5 \mathrm{~mm}$ thick acrylic plate and placed at the centre of the $\gamma$-beam. The TL emission was measured in the step-heating mode. The intensity of the TL emission was evaluated by integrating the area under the peak appearing in the second region as seen in Figure 4b. TL response was defined as the TL intensity per unit of mass $\left(\mathrm{nC}^{\mathrm{mg}} \mathrm{m}^{-1}\right)$. In order to guarantee the complete release of the charge carriers from the trap levels, the pellets were annealed at $400{ }^{\circ} \mathrm{C}$ during 1 hour after the TL reading.

The reproducibility of the TL readings related to five irradiations at $10 \mathrm{mGy}$ of ${ }^{137} \mathrm{Cs}$ is shown in Figure 5. The mean values of TL responses accompanied by the respective standard deviations are shown for all specimens. The central line indicates the mean value of all measurements $(\bar{X})$ and the outer lines indicate $\bar{X} \pm s$ and $\bar{X} \pm 2 s$ ranges; where $s$ is the standard deviation related to all measurements. Analysing the results shown in Figure 5a, the criteria adopted for sample exclusion were: (i) dispersion in individual TL response higher than $9 \%$; (ii) mean value of the TL response out of the range $\bar{X} \pm s$. The rejected pellets (11) are marked by a square in this figure. The mean of the TL response of the batch composed by the nineteen selected pellets was $(9.26 \pm 0.62) \mathrm{nC} \cdot \mathrm{mg}^{-1}$. The dispersion in TL response of each

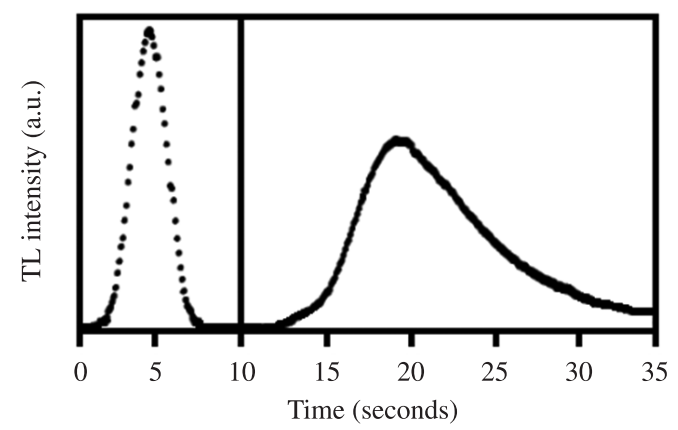

(b) $10 \mathrm{mGy}$ of $\gamma$-rays $\left({ }^{137} \mathrm{Cs}\right)$

Figure 4. TL glow curves of quartz-pellets recorded at slope- (a) and step-heating modes (b). 


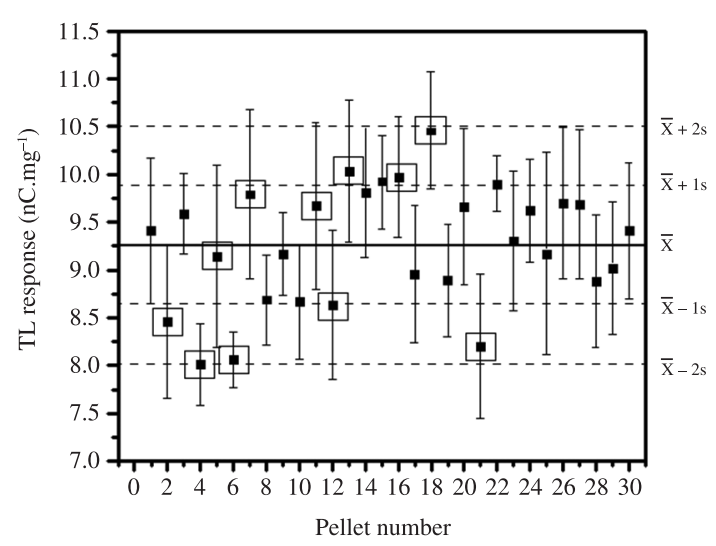

(a) 5 cycles; 30 pellets

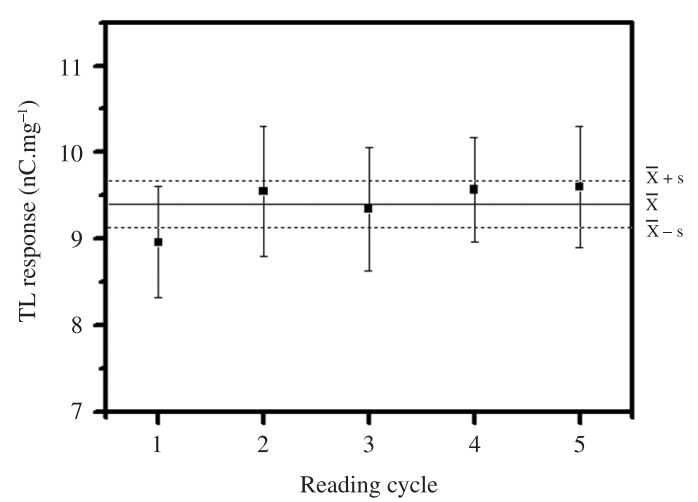

(b) Selected pellets

Figure 5. Mean values of TL response of five annealing-irradiation-reading cycles with quartz-pellets. Absorbed dose: $10 \mathrm{mGy}$ of ${ }^{137} \mathrm{Cs}$.

pellet is ranged between 3.1 and $8.3 \%$. In fact, this dispersion is not exclusively related to the batch heterogeneity itself but it also reflects the fluctuation related to the procedures of irradiation and TL read-out. According to Furetta ${ }^{28}$, the evaluation of the batch heterogeneity can be estimated by means of a detector variability index (DVI) as follows:

$$
D V I=\sqrt{(S V I)^{2}-(R V I)^{2}}
$$

where SVI (system variability index) is the mean value of the percent standard deviations of each specimen and $R V I$ (reader variability index) is the percent standard deviation of the mean values of each cycle of reading. SVI was calculated from the values shown in the Figure 5a. $R V I$ was calculated from Figure 5b, which shows the repeatability attained after each reading cycle with the selected pellets. Thus, it was found $S V I=6.57 \%, R V I=2.70 \%$ and $D V I=5.99 \%$. Using the same procedure, Furetta ${ }^{28}$ obtained $D V I=0.98 \%$ for a batch of 10 specimens of TLD-100 (Harshaw) dosimeters (10 cycles) and Nascimento et al. ${ }^{14}$ found $D V I=1.57 \%$ for 61 sensitized quartz single-crystals related to 5 cycles. Thus, it is concluded that the dispersion of TL readings shown in Figure 5 is mainly associated with the heterogeneity of the batch of quartz-pellets. This result shows that further improvements are required in the manufacturing process in order to improve the reproducibility in dose assessment with quartz-pellets.

Figure 6 shows the TL response as a function of the stored time after irradiation. The selected pellets were irradiated with a test-dose of $10 \mathrm{mGy}$ using the ${ }^{137} \mathrm{Cs}$ irradiator. Three pellets were measured after irradiation (1 hour) and the others were stored in the dark at $(23 \pm 2){ }^{\circ} \mathrm{C}$. Then, they were read after 1, 7, 14, 30, 45 and 60 days using the step-heating mode. It is noticed that the TL response decreases between 1 and 30 days and then stabilizes around a certain value that is approximately $8 \%$ lower than the TL read-out after 1 hour. As the pellets were stored in the dark at a temperature that is much lower than that of the sensitized peak, the decay observed in Figure 6 cannot be associated neither to optical bleaching nor thermal release of trapped carriers at ambient temperature. The TL decay due to all other environmental conditions except temperature and light exposure has been termed anomalous fading ${ }^{29}$. Previously,

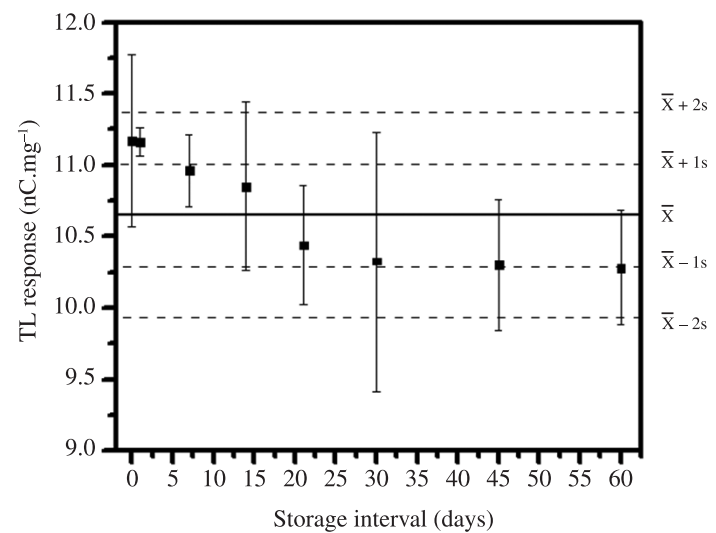

Figure 6. Stability of TL response of quartz-pellets irradiated with $10 \mathrm{mGy}$ of ${ }^{137} \mathrm{Cs}$.

the TL response measured with single-crystal specimens of Solonópole quartz did not show this effect for a storage time of 120 days after irradiation ${ }^{30}$. For some unknown reason, the stored TL signal in quartz-pellets is less stable than in single-crystal discs. Compared to other dosimeters, quartz-pellets shows slightly higher fading than that has been reported to $\mathrm{LiF}: \mathrm{Mg}, \mathrm{Ti}, \mathrm{BeO}, \mathrm{CaSO}_{4}: \mathrm{Dy}, \mathrm{LiF}: \mathrm{Mg}, \mathrm{Cu}, \mathrm{P}$ and $\mathrm{Al}_{2} \mathrm{O}_{3}: \mathrm{C}$ by several authors ${ }^{2,4}$. Nevertheless, this fading is three times lower than that reported by sintered pellets of $\mathrm{Al}_{2} \mathrm{O}_{3}{ }^{[31]}$.

\subsection{Linearity, sensitivity and detection limit}

The analysis of the linearity of the TL response as a function of the absorbed dose is shown in Figure 7. This study was carried out with $\gamma$-rays in two ranges of doses, as follows: from 0.5 to $30 \mathrm{mGy}$ using the ${ }^{137} \mathrm{Cs}$ irradiator, and from 25 to $200 \mathrm{mGy}$ using the ${ }^{60} \mathrm{Co}$ irradiator. The sequence annealing-irradiation-reading was repeated three times for each dose. For comparison, three TLD-100 specimens were annealed, irradiated and read together with the quartz-pellets. TL emissions were measured in the step-heating mode. The angular coefficient $(b)$ and the regression coefficient $\left(R^{2}\right)$ of the linear fittings are also shown in Figure 7. It is observed that quartz-pellets show a 


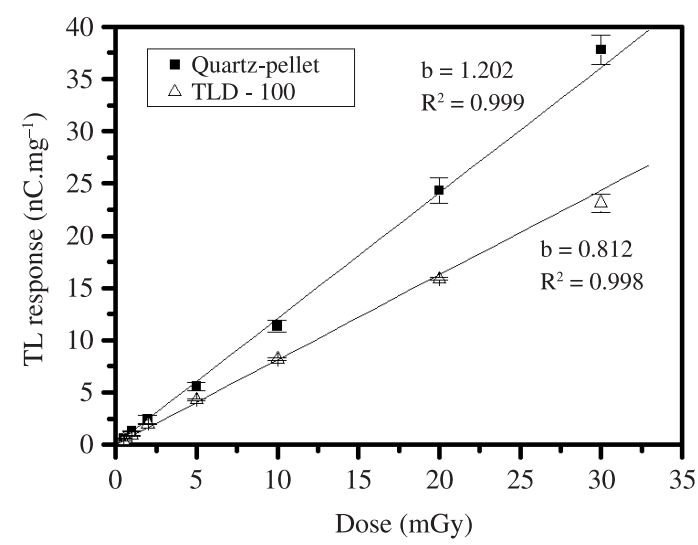

(a) $\gamma$-rays of ${ }^{137} \mathrm{Cs}$

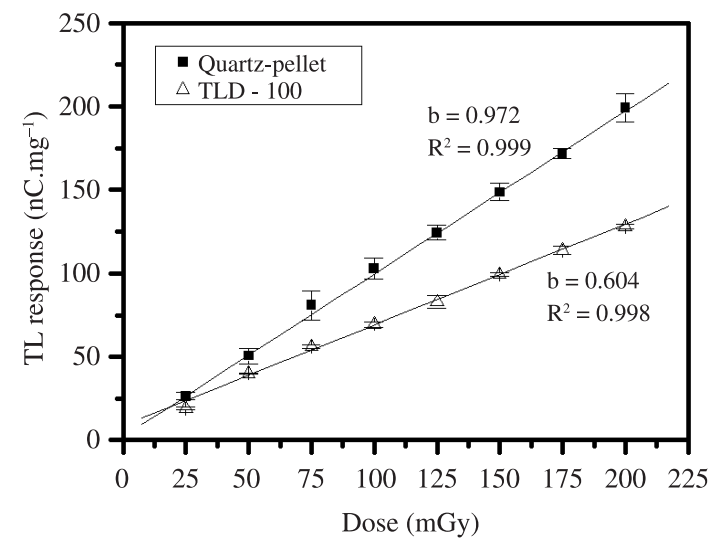

(b) $\gamma$-rays of ${ }^{60} \mathrm{Co}$

Figure 7. TL response as a function of absorbed dose of quartz-pellets and TLD-100.

linear TL response for the whole range of dose investigated here. Comparing the angular coefficients of each curve, it is observed that the sensitivity of the quartz-pellets is 1.6 times higher than that of TLD-100. This sensitivity is slightly lower than that found for sensitized single-crystals, which is 1.8 higher than TLD-100 measured in similar conditions $\mathrm{s}^{30}$. Nevertheless, this sensitivity is still lower than that usually found for high sensitivity TLD material such as $\mathrm{CaSO}_{4}$ :Dy, $\mathrm{LiF}: \mathrm{Mg}, \mathrm{Cu}, \mathrm{P}$ and $\mathrm{Al}_{2} \mathrm{O}_{3}: \mathrm{C}^{2,4}$.

The lower limit of detection of a TLD is currently defined as the background value plus three times the standard deviation $^{29}$. The TL reading of the background of the whole batch of quartz-pellets was $(2.90 \pm 0.65) \mathrm{nC}$. Considering the dose response curve shown in Figure $7 \mathrm{a}$, the detection limit of quartz-pellets for $\gamma$-rays is close to $3.6 \mathrm{mGy}$. Using similar experimental conditions, the detection limit found by Nascimento ${ }^{30}$ for sensitized single-crystals and TLD-100 was 0.009 and $0.028 \mathrm{mGy}$, respectively. By studying the variability of the TL signal in-non irradiated pellets, the lowest detectable value for sintered $\mathrm{Al}_{2} \mathrm{O}_{3}$ pellets was $10 \mathrm{mGy}^{31}$. Similarly, it was reported that the detection threshold for $\mathrm{LiF}: \mathrm{Mg}, \mathrm{Cu}, \mathrm{P}$ was close to $0.06 \mathrm{mGy}^{32}$. In case of the highest level of detection, it is higher than $200 \mathrm{mGy}$ because no evidence of saturation of the TL response with dose is seen in Figure 7b.

\subsection{Energy dependence}

The relationship between TL response and photon-energy is an important consideration for those materials to be used in personal or clinical dosimetry where human

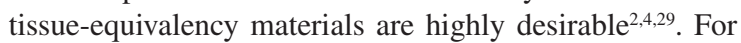
the study of photon-energy dependence, quartz-pellets and TLD-100 were simultaneously irradiated with doses ranging from 1 to $8 \mathrm{mGy}$. Irradiations with X-rays were performed using a HF 420 Pantak X-ray generator, according to the ISO 4037-1 narrow series X-ray beams, with effective energies varying from 16 to $118 \mathrm{keV}$. Irradiations with $\gamma$-rays were carried out with ${ }^{137} \mathrm{Cs}(662 \mathrm{keV})$ and ${ }^{60} \mathrm{Co}(1220 \mathrm{keV})$ sources. The sequence annealing-irradiation-reading was repeated three times for each dose and photon-energy. The TL emission was measured in the step-heating mode. Figure 8 shows the energy dependences of quartz-pellets

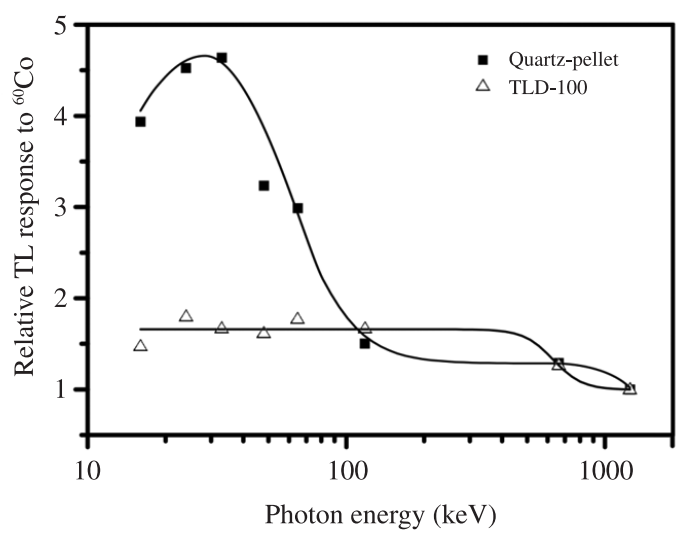

Figure 8. R elative TL response of quartz-pellets and TLD-100 as a function of photon-energy.

and TLD-100 given with respect to the response of ${ }^{60} \mathrm{Co}$. This figure was obtained by using the angular coefficients of the respective dose-response curves. It is seen that quartz-pellets shows higher energy dependence than TLD-100, which is approximately five times higher at $33 \mathrm{keV}$. For photon radiation, the material factor governing the energy dependence is the effective atomic number $\left(Z_{\text {eff }}\right)$, which dictates the amount of energy absorbed by the material in a given radiation field. The higher the value of $Z_{\text {eff }}$ and the lower the energy of incident photons, the larger is the TL response to a given dose due to the dominant component of the photoelectric effect in the mass energy absorption coefficient ${ }^{2,29}$. The values of $Z_{\text {eff }}$ calculated for LiF- and $\mathrm{SiO}_{2}$-based materials are close to 8.3 and 11.8, respectively ${ }^{4}$. A similar behavior was previously reported for quartz single-crystals ${ }^{14}$. Compared to others TLD materials, the energy dependence found to quartz-pellets is similar to $\mathrm{Al}_{2} \mathrm{O}_{3}$ and lower than $\mathrm{CaF}_{2}: \mathrm{Mn}$ and $\mathrm{CaSO}_{4}: \mathrm{Dy}^{2,4}$. The overestimation of dose resultant from the photon-energy dependence can be mitigated by the correct use of filters and appropriate algorithms for the dose assessment in personal dosimetry. In the case of clinical applications, this problem can be overcome by using TL response curves obtained with specific photon energies. 


\section{Summary}

The results of this study showed that the procedure to manufacture composite pellets of $75 \times 150 \mu \mathrm{m}$ quartz particles bonded with flocculated PTFE is feasible and can be adopted to produce discs with dimensions that are suitable to TL dosimetry. Based on vibration tests and surface integrity analyses, it was shown that the quartz-pellets produced by cold-pressing and heat-treatments at $400{ }^{\circ} \mathrm{C}$ have suitable resistance to be manipulated during TLD procedures. Besides the particle size itself, it has been seen that the homogeneous distribution of particles with the binding matrix is an important aspect to avoid mechanical fragility and to improve the uncertainty related to the assessment of the absorbed dose.

The glow curve analysis showed that quartz-pellets have a strong and isolated peak appearing nearby $300{ }^{\circ} \mathrm{C}$. This peak is not affected by the PTFE matrix and has a satisfactory thermal stability up to $400{ }^{\circ} \mathrm{C}$ indicating that it can be reused many times in TLD procedures. The reproducibility study carried out here revealed that the uncertainty in dose assessment with these pellets $( \pm 6 \%)$ is higher them that acceptable for clinical applications $( \pm 3.5 \%)$ but much better than the uncertainty required in radiation processing in industry $( \pm 15 \%)$. The dispersion related to the dose assessment is probably associated with a non-uniform distribution of quartz grains on the surface of the pellets. This effect is higher than the dispersion observed in single-crystal specimens which has been attributed to the variation in the concentration of point defects related to the TL emission of the sensitized peak. On its turn, the fading associated with the TL signal of quartz-pellets $(8 \%)$ is slightly higher than the required value of $5 \%$ over the monitoring period at $25^{\circ} \mathrm{C}$.

\section{References}

1. Daniels F, Boyd CA and Saunders DF. Thermoluminescence as a research tool. Science. 1953; 117(3040):343-349 PMid:17756578. http://dx.doi.org/10.1126/ science.117.3040.343

2. Mahesh K, Weng PS and Furetta C. Thermoluminescence in solids and its applications. Ashford: Nuclear Technology Publishing; 1989.

3. Campos LL. Termoluminescência de materiais e suas aplicações em dosimetria da radiação. Cerâmica. 1998; 44(290):1-21.

4. Bos AJJ. High sensitivity thermoluminescence dosimetry. Nuclear Instruments and Methods in Physics Research B: Beam Interactions with Materials and Atoms. 2001; 184(1-2):3-28.

5. Ranogajec-Komor M. Thermoluminescence Dosimetry-Application in environmental monitoring. Radiation Safety Management. 2003; 2(1):2-16.

6. Moscovitch M and Horowitz YS. Thermoluminescent materials for medical applications: $\mathrm{LiF}: \mathrm{Mg}$,TiandLiF:Mg,Cu,P. Radiation Measurements. 2007; 41:71-77. http://dx.doi. org/10.1016/j.radmeas.2007.01.008

7. McKeever SWS. Thermoluminescence in quartz and silica. Radiation Protection Dosimetry. 1984; 8(1-2):81-98.

8. Wintle AG. Luminescence dating: laboratory procedures and protocols. Radiation Measurements. 1997; 27(5-6):769-817. http://dx.doi.org/10.1016/S1350-4487(97)00220-5
Compared to vanguard TLD materials such as $\mathrm{LiF}: \mathrm{Mg}, \mathrm{Cu}, \mathrm{P}$ and $\mathrm{Al}_{2} \mathrm{O}_{3}: \mathrm{C}$, further improvements in the manufacturing process of quartz-pellets are required to improve the reproducibility and stability of their TL response.

The linearity of the TL response with absorbed dose and the analysis of the detection limits indicate that quartz-pellets are reliable to assess doses from 4 to $200 \mathrm{mGy}$ which is the range of dose commonly used in clinical dosimetry. The TL response curves obtained with different photon-energies showed that the sensibility of the quartz-pellets is higher than that found for TLD-100. The effect of the photon-energy dependence can be corrected by the appropriate use of filters, algorithms or appropriate calibration curves. Thus, the higher sensitivity of quartz-pellets for photon-energies lower than $100 \mathrm{keV}$ cannot be considered a drawback to their use in clinical applications such as radiodiagnostics.

Therefore, the actual dosimetric properties and the simple manufacturing process described here together with the access to high-grade crystals in Brazil, give good reasons to consider quartz-pellets as a candidate for TL dosimetry in radiation processing applications involving sterilization, food processing and material testing. Additional efforts with respect to batch homogeneity and TL response stability should be done in order to expand its use to clinical dosimetry.

\section{Acknowledgements}

The authors would like to thank Cinara Guimarães (DEN/UFPE) for her assistance with TL read-outs. The authors ABCJr and TFB are grateful to CAPES and PIBIC/ $\mathrm{CNPq} / \mathrm{CETEM}$ to the scholarship provided. This work was supported by CNPq, FACEPE and LMRI/UFPE.

9. Preusser F, Chinthambo ML, Gotte T, Martini M, Ramseyer K, Sendera EJ et al. Quartz as a natural luminescence dosimeter. Earth-Science Reviews. 2009; 97(1-4):196-226. http://dx.doi. org/10.1016/j.earscirev.2009.09.006

10. Soika $\mathrm{C}$ and Delincée $\mathrm{H}$. Thermoluminescence analysis for detection of irradiated food- Luminescence characteristics of minerals for different types of radiation and radiation doses. LWT - Food Science and Technology. 2000; 33:431-439.

11. Khoury HJ, Guzzo PL, Barreto SB and Hazin CA. Effect of high gamma doses on the sensitisation of natural quartz used for thermoluminescence dosimetry. Radiation Effects \& Defects in Solids. 2007; 162(2):101-107. http://dx.doi. org/10.1080/10420150601035490

12. Guzzo PL, Khoury HJ, Miranda MR, Barreto SB and Shinohara AH. Point defects and pre-dose requirements for sensitization of the $300{ }^{\circ} \mathrm{C}$ TL peak in natural quartz. Physics and Chemistry of Minerals. 2009; 36(2):75-85. http://dx.doi.org/10.1007/ s00269-008-0259-x

13. Khoury HJ, Guzzo PL, Souza LBF, Farias TMB and Watanabe S. TL dosimetry of natural quartz sensitized by heat-treatment and high dose irradiation. Radiation Measurements. 2008; 43(2-6):487-491.

14. Nascimento SRV, Souza LBF, Guzzo PL and Khoury H J. Study of dosimetric properties of sensitized Solonópole quartz. In: Proceedings of the 2009 International Nuclear Atlantic Conference; 2009; Rio de Janeiro. Rio de Janeiro; 2009. p. 1-9. 
15. Carvalho Junior AB, Guzzo PL, Sullasi HL and Khoury HJ. Effect of particle size in the TL response of natural quartz sensitized by high gamma radiation and heat-treatment. Materials Research. 2010; 13(2):265-271. http://dx.doi. org/10.1590/S1516-14392010000200023

16. Jani MG, Halliburton, LE and Kohnke EE. Point defects in crystalline $\mathrm{SiO}_{2}$ : Thermally stimulated luminescence above room temperature. Journal of Applied Physics. 1983; 54(11):6321-6328. http://dx.doi. org/10.1063/1.331906

17. McKeever SWS, Chen CY and Halliburton LE. Point defects and pre-dose effect in natural quartz. Nuclear Tracks and Radiation Measurements. 1985; 10(4-6):489-495. http://dx.doi. org/10.1016/0735-245X(85)90047-X

18. Guzzo PL, Iwasaki F and Iwasaki H. Al-related centers in relation to $\gamma$-irradiation: Response in natural quartz. Physics and Chemistry of Minerals. 1997; 24(4):254-263 http://dx.doi. org/10.1007/s002690050037

19. Souza LBF, Guzzo PL and Khoury HJ. Correlating the TL response of $\gamma$-irradiated natural quartz to aluminum and hydroxyl point defects. Journal of Luminescence. 2010; 130:1551:1556.

20. Shambon A and Condon W. LiF pellet dosimeter. Physics in Medicine and Biology. 1968; 13(4):653-656. PMid:5683333. http://dx.doi.org/10.1088/0031-9155/13/4/415

21. Yang JS, Kim DY, Kim JL, Chang SY, Nam YM and Park JW. Thermoluminescence characteristics of Teflon embedded $\mathrm{CaSO}_{4}$ :Dy TLD. Radiation Protection Dosimetry. 2002; 100(1-4):337-340. http://dx.doi.org/10.1093/ oxfordjournals.rpd.a005883

22. Fukimori DT and Camnpos LL. Study of dosimetric properties of $\mathrm{CaSO}_{4}: \mathrm{Mn}$ pellets produced at IPEN. In: Proceedings of the 2007 International Nuclear Atlantic Conference; 2007; Santos. Santos; 2007. p. 1-6.

23. Carvalho Junior AB, Guzzo PL and Khoury HJ. Obtenção de discos policristalinos de quartzo Natural para dosimetria das radiações ionizantes. In: Anais do XXII Encontro Nacional de Tratamento de Minério e Metalurgia Extrativa; 2007; Ouro Preto. Ouro Preto; 2007. vol. 1, p. 767-774.

24. Carvalho Junior AB. Preparação e caracterização de quartzo particulado e discos quartzo-teflon para dosimetria termoluminescente das radiações ionizantes. [Tese]. Recife: Universidade Federal de Pernambuco; 2010.

25. David $M$ and Sunta CM. Quartz dosimeter for archaeological dating. Nuclear Tracks and Radiation Measurements. 1985; 10(4-6):625-629.

26. Yazici AN and Topaksu M. The analysis of thermoluminescence glow peaks of unannealed synthetic quartz. Journal of Physics D: Applied Physics Radiation. 2003; 36(6):620-627.

27. Guzzo PL, Souza LBF and Khoury HJ. Kinetic analysis of the $300{ }^{\circ} \mathrm{C}$ TL peak in Solonópole quartz sensitized by heat and gamma radiation. Radiation Measurements. 2011; 46(12):1421-1425. http://dx.doi. org/10.1016/j.radmeas.2011.02.024

28. Furetta C. Handbook of thermoluminescence. New Jersey: World Scientific; 2003. http://dx.doi.org/10.1142/9789812564863

29. Mckeever SWS. Thermoluminescence of solids. Cambridge University Press; 1985. http://dx.doi.org/10.1017/ CBO9780511564994

30. Nascimento SRV. Dosimetria termoluminescente do quartzo natural de Solonópole (CE) para aplicação em radiodiagnóstico. [Dissertação]. Recife: Universidade Federal de Pernambuco; 2010.

31. Rocha FDG and Caldas LVE. Characterization of $\mathrm{Al}_{2} \mathrm{O}_{3}$ sintered pellets for dosimetric applications in radiotherapy. Journal of Radiological Protection. 1999; 19(1):51-55. PMid:10321696. http://dx.doi.org/10.1088/0952-4746/19/1/006

32. Azorin J, Gutiérrez A, Niewiadomski T and González P. Dosimetric characteristics of $\mathrm{LiF}: \mathrm{Mg}, \mathrm{Cu}, \mathrm{P}$ TL phosphor prepared at ININ, Mexico. Radiation Protection Dosimetry. 1990; 33(1-4):283-286. 